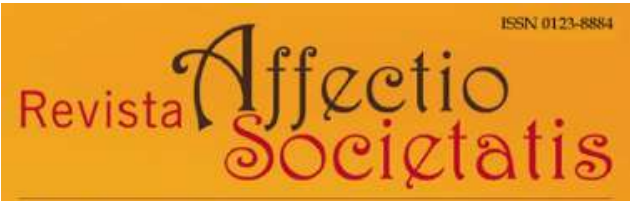

Departamento de Psicoanálisis I Universidad de Antioquia

Revista Affectio Societatis

Departamento de Psicoanálisis

Universidad de Antioquia

revistaaffectiosocietatis@udea.edu.co

ISSN (versión electrónica): 0123-8884

Colombia

2019

Sylvia De Castro Korgi

\title{
UN IMPOSIBLE DUELO
}

Revista Affectio Societatis, Vol. 16, N. ${ }^{\circ}$ 30, enero-junio de 2019

Art. \# 11 (pp. 208-221)

Departamento de Psicoanálisis, Universidad de Antioquia

Medellín, Colombia 


\title{
UN IMPOSIBLE DUELO
}

\author{
Sylvia De Castro Korgi ${ }^{1}$ \\ Universidad Nacional de Colombia, Bogotá \\ sylviadecastro@gmail.com \\ ORCID: 0000-0002-9947-1165
}

DOI: 10.17533/udea.affs.v16n30a11

\section{Resumen}

Teniendo como marco histórico el conflicto armado en Colombia, el artículo trata acerca del duelo truncado en casos de desaparición y, tomando apoyo en un cuento literario y un documental, muestra cómo mediante un ritual popular de enterramiento de cadáveres de desconocidos que flotan en los ríos, los habitantes de los puertos aparecen como los repre- sentantes de una humanidad que se niega a entregarle a la barbarie el último baluarte de una costumbre, en el sentido ético del término, que nos ha permitido mantenernos a salvaguarda de esa lógica: la costumbre de la sepultura.

Palabras clave: duelo, desaparición, conflicto armado, literatura

\section{AN IMPOSSIBLE MOURNING}

\section{Abstract}

Having as a context the armed conresenting a humanity which refuses flict in Colombia, this paper addresses the truncated mourning in cases of disappearance. Supported on a literary tale and on a documentary, it presents how, through the popular ritual of burying the corpses of unknown people floating on the rivers, the riverside dwellers appear as repto give to barbarity the last bastion of a custom, in the ethical sense of the term, that has allowed us to be safe from that logic: the custom of the burial.

Keywords: mourning, disappearance, armed conflict, literature.

1 Psicoanalista. Profesora de la Escuela de Estudios en Psicoanálisis y Cultura. Miembro del Grupo de Investigación "Psicoanálisis y cultura", Universidad Nacional de Colombia (sede Bogotá). 


\section{UN DEUIL IMPOSSIBLE}

\section{Résumé}

Cet article s'inscrit dans le cadre du conflit armé en Colombie, et aborde le deuil tronqué dans les cas de disparition forcée. En prenant appui sur un récit littéraire et sur un documentaire, le texte montre comment, grâce à un rituel populaire d'enterrement de cadavres d'inconnus qui flottent dans les rivières, les riverains apparaissent comme les représentants d'une humanité qui refuse de céder à la logique de la barbarie le dernier bastion d'une coutume (dans un sens éthique) qui leur a permis de se protéger contre cette même logique : la coutume de la sépulture.

Mots-clés : deuil, disparition forcée, conflit armé, littérature.

Recibido:15/03/2018 • Aprobado:31/10/2018 
Contra la fugacidad, la letra

Contra la muerte, el relato.

Tomás Eloy Martínez

I.

Me propongo acudir a la reflexión freudiana sobre el duelo en un momento en que nuestra experiencia histórica más reciente, la de una guerra irregular que ha llegado parcialmente a su fin en virtud de un esforzado acuerdo de paz, nos permite - con cierta esperanza - volver el rostro a lo que viene después del fulgor del combate, si asumimos que la estela de dolor no equivale al proceso de duelo. En virtud de la diferencia entre el dolor y el duelo, entre la aflicción causada por la pérdida y el duelo que, aun contando con el dolor, implica un cierto proceso psíquico, una cierta reestructuración psíquica del doliente, es acertado preguntarse, en estos días justamente, por la incidencia del acuerdo de paz sobre las víctimas porque, más allá de los aspectos jurídicos (cf. Agamben, 2000, pp. 16-17)², reconocimiento de las víctimas mediante y promesa de aproximación a la verdad de los crímenes, ¿no promete acaso la firma misma del acuerdo la transición a otro momento en el que el dolor de paso al duelo? Quizás podríamos ver en ello el verdadero alcance de un acuerdo de paz que ha situado a las víctimas del conflicto en el centro de sus preocupaciones. La apuesta, pues, no ha sido cualquier cosa, considerando el tamaño de nuestra tragedia.

El duelo, entonces. Según sabemos, Freud adjudica al duelo el carácter de una reacción ante la pérdida de un ser querido o de una abstracción equivalente, como lo es el caso de un proyecto, de un ideal, la patria o la libertad, abstracción que ocupa un lugar privilegiado cuya falta provoca el duelo en virtud del sentido y del valor que el sujeto le reconoce. $\mathrm{Al}$ respecto, no puedo pasar por alto el talante dolido de

2 Imposible no recordar en este punto la reflexión agambeniana en relación con el uso de las categorías jurídicas: Agamben advierte que el derecho no tiende al establecimiento de la justicia, tampoco al de la verdad, exclusivamente a la celebración del juicio. 
esa comunicación titulada "La desilusión provocada por la guerra", una de las dos que bajo el título "De guerra y muerte. Temas de actualidad" Freud publica a pocos meses del estallido de la primera guerra mundial. En ella reconoce una pérdida así, anudada al socavamiento de los ideales de la eticidad, del cuidado del bien común y de la aceptación de las diferencias entre las naciones, pérdida de la que se conduele en grado apenas coherente con los horrores que el combate fue capaz de provocar.

En efecto, Freud señala cómo esa guerra no fue menos cruel que otras, al contrario, transgredió un límite acogido por lo que ya para entonces se designaba como derecho internacional, lo cual era para él indicador de cómo las naciones cultas contribuían a la barbarie. Así las cosas, y sobre el fondo del desmoronamiento de la fugaz esperanza de una "guerra ideal", Freud (1915/1992) concluye que la desilusión provocada por la guerra "(...) no está justificada, pues consiste en la destrucción de una ilusión” (p. 282).

Con la guerra nos hallamos, pues, sin velo ante el horror del que la humanidad es capaz. Según la elaboración freudiana, la guerra nos deja turbados ya no solo porque nos confronta con la muerte de una manera insoportable, sino porque nos enfrenta sin remedio ante las manifestaciones de odio que resultan ajenas a nuestros ideales de civilidad. La guerra, la Gran guerra, como sabemos, interrumpió toda legislación, con lo que eso tuvo como consecuencia a título del desfondamiento del Otro de la ley, del Otro del pacto social, lo cual no fue ajeno a la paulatina desaparición del dominio de lo público que hasta entonces había funcionado como recurso simbólico para quienes se hallaran en duelo (cf. Elmiger, 2011, p. 31-50). Freud no lo dice explícitamente, pero esa modificación de las cosas, hoy en día debidamente documentada, es el telón de fondo de sus elaboraciones. Por lo demás, nosotros sabemos lo que en Europa ya se anunciaba, por increíble que fuera, y lo que ocurrió. Con todo, aquí, en Colombia, la barbarie de la guerra no dejó de sorprendernos...

Ahora bien, es en relación con la pérdida de un ser querido, del objeto de nuestro amor, de nuestra ventura, cualquiera sea el lugar que ocupe en el entramado de las relaciones sociales, que el asunto del due- 
lo se plantea para Freud de forma explícita. No nos resultará entonces difícil diferenciar el ideal que pierde su vigencia, del semejante cuyo cuerpo se entierra, aún si muchos colombianos nos vestimos de luto el 2 de octubre de 2016, cuando el No se impuso sobre el Sí en el plebiscito que buscaba refrendar los acuerdos de paz de La Habana. Quizás podemos intentar una aproximación conclusiva al respecto y afirmar que entre el ideal que se pierde y el agujero en lo real abierto por la ausencia del otro, del semejante al que debemos enterrar, una diferencia radical se plantea: al fin de cuentas la pérdida de los ideales es un asunto al que estamos expuestos más o menos de manera cotidiana, cuando caen los velos que entre tanto los engalanaban. Otra cosa es la muerte del semejante, de aquel para quien no hay sustitución posible, del que no puede anhelarse ninguna recuperación, uno de cuyos asuntos fundamentales es el cadáver, es decir, en relación con los ritos de enterramiento, con lo cual el panorama de nuestra tragedia se va perfilando... Esa es al menos la ruta en la que me comprometo en este texto.

Todavía, en el tratamiento del asunto en "Duelo y melancolía", Freud (1917/1992, p. 176) introduce la noción de 'trabajo de duelo', esa suerte de exigencia que se le impone al doliente en relación con la pérdida, y que aparece primero en su pluma como "trabajo de recuerdo" (cf. Batista, 2011, p. 17-30). Se trata, según sabemos, del privilegio que él le concede al desasimiento paulatino de la libido que anudó los lazos con el muerto, de cada recuerdo, uno a uno, desasimiento doloroso, que compromete al deudo en lo más profundo de sí, y del que podríamos destacar dos elementos para nuestro propósito.

En primer lugar, que tal aflojamiento de los lazos exige un trabajo de memoria, allí donde a primera vista pareciera de olvido. Freud (1917/1992, p. 243) dice explícitamente que los recuerdos y las expectativas en que la libido se anudaba al objeto no son clausurados, al contrario, son sobreeinvestidos, es decir, que la sobreinvestidura de los recuerdos es condición de su clausura ${ }^{3} . .$. Con lo cual el asunto de la memoria del muerto queda situado en una articulación inevitable con el duelo. Quiero decir entonces que el "trabajo del duelo"

3 Agradezco a mi colega Mario Figueroa por esta indicación. 
riñe con una idea de "enterrar la memoria" que los deudos guardan de sus muertos, una memoria tanto más presente y acuciante cuanto que los crímenes no han sido esclarecidos y sus cuerpos no han sido siquiera hallados... (cf. Gaitán, 2017). Aquello que espera ser enterrado, en este país, a despecho de lo que anhelan quienes operaron como "determinadores" de los crímenes, no es la memoria de desapariciones y asesinatos, son los muertos.

En segundo lugar, de ese desasimiento paulatino dice Freud que avanza, ahora sí, en una suerte de desprendimiento y culmina, finalmente, en una renuncia de lo perdido en virtud de la cual la libido, una vez libre, estaría dispuesta a la sustitución del objeto. Freud se muestra, pues, a favor de la sustitución del objeto perdido, sustitución apoyada, por lo demás, en los buenos servicios del examen de realidad, lo cual no deja de ser extraño... pues, ¿quién no recuerda su original reflexión sobre la realización del deseo y sobre el objeto que se constituye en esa experiencia inaugural, un objeto que no es otra cosa que la huella de memoria de un encuentro para siempre perdido? (cf. Rabinovich, 2003, pp. 12-14).

Pero, entonces, tampoco es de extrañar que el propio Freud, en virtud de su propia experiencia, haya podido interrogar el final prometedor de la sustitución del objeto perdido al término del proceso de duelo. De hecho, una carta suya, no un texto conceptual ni un informe doctrinario, nos conduce al propio duelo de Freud por la muerte de su hija Sophie, un duelo que viene a subvertir sus convicciones. En 1929, le escribe a su amigo Ludwig Binswanger, él mismo en duelo por la muerte de uno de sus hijos, estas palabras:

Aunque sabemos que después de una pérdida así el estado agudo de pena va aminorándose gradualmente, también nos damos cuenta de que continuaremos inconsolables y que nunca encontraremos con qué rellenar adecuadamente el hueco, pues aún en el caso de que llegara a cubrirse totalmente, se habría convertido en algo distinto. Así debe ser. Es el único modo de perpetuar los amores a los que no deseamos renunciar (Freud, 1893-1939/1963, p. 431).

Digamos entonces que aun en el duelo que Freud califica de normal, aspirar a la sustitución del objeto perdido por otro, una sustitución sin 
resto, no es más que... vana ilusión. La muerte revela que algo del objeto perdido es inolvidable, por lo tanto, insustituible. Lo es porque el objeto no se reduce a representación. Lo irrepresentable del otro, eso que Michael Turnheim llama la alteridad, la irreductible singularidad del otro, eso, antes que resolverse gracias al trabajo de duelo, lo moviliza...

Tal constatación nos obliga a volver sobre las formulaciones freudianas de la segunda comunicación recogida en el texto ya citado "De guerra y muerte", en este caso "Nuestra actitud hacia la muerte", en el que se hace explícita la doble vertiente de la muerte, la propia y la del otro, para advertir que no es solo la primera, la propia -de la que sabemos que no hay registro en el inconsciente- la que nos resulta irrepresentable. También la irrupción de la muerte del otro nos revela una parte suya que escapa a la representación. ¿No es esa acaso la impresión ante la que nos arroja la presencia misma del muerto? Impresión de extrañeza, por decir lo menos.

Con estos elementos en juego, una conclusión se advierte, relativa a la doble desdicha que es para nosotros la muerte de alguien que nos es próximo pues, por un lado, nos pone frente a la alteridad de la muerte, es decir, de lo no representable a nivel de lo universal -aquello en relación con lo cual el hombre de los orígenes fabricó espíritus y demonios ( $c f$. Freud, 1913/1991, p. 65)-, mientras que de otro lado nos enfrenta a la presencia de lo que permanece, de un resto del muerto, a nivel de lo particular, un resto que no se deja eliminar... (cf. Turnheim, 2002). Lo real del muerto, a lo que habría que sumarle la particularidad de nuestro encuentro con él y de lo que hemos sido para él, lo hacen refractario a la sustitución (cf. León-López, 2011, pp. 67-76). En verdad, es imposible hacer el duelo cabal del otro de una relación en la que cada uno aporta su alteridad, es decir, en la que cada uno aporta, justamente, lo insustituible...

Pero lo que en adelante quisiera destacar es cómo esa alteridad plantea problemas a la memoria, que no sabe qué hacer con lo que no es representación o, incluso, que no puede hacer nada a falta de representación ( $c f$. Turnheim, 2002). Ahora, según creo, retroactivamente cobra pertinencia lo que he dicho hasta aquí. En adelante se abre el otro capítulo, ineludible, del duelo: el de los rituales de en- 
terramiento, los que se nos revelan como intentos de tratar, de bordear lo irrepresentable de la muerte, con lo cual nos aproximamos al asunto doloroso que se nos presenta, en Colombia, como una herida abierta, una vergüenza, una deuda con las víctimas del conflicto.

Este tema, el de la memoria de los muertos, del cuidado del cadáver, del entierro, agrega a la comprensión hasta aquí presentada, un tanto dual del duelo puesto que se juega entre el deudo y su muerto, elementos que Freud puso en principio a la cuenta de su examen sobre el desarrollo de la cultura. En "Tótem y tabú" rastrea entre los llamados primitivos la existencia del tabú de los muertos y la serie de limitaciones, prohibiciones y mandamientos a los que este conduce y que se manifiestan durante el período de duelo. Freud (1913/1991, p. 67) asegura que no se puede responsabilizar al duelo por las prácticas del tabú, pero también afirma que estas, dado su carácter de restricciones, dan expresión al duelo. Este hallazgo nos pone en la pista de la historicidad de las formas que asume el duelo, sus rituales, $\mathrm{y}$, simultáneamente, de lo que constituye su invariante: el tratamiento del cadáver. El duelo, pues, como Freud lo consigna, atañe tanto al afecto penoso como a su manifestación ritual.

El asunto de los rituales no es ajeno a lo que Freud llama la prueba de realidad. El trabajo de duelo cumple con una función, la de admitir como perdido lo que se ha perdido, admitir también que no retornará, y eso equivale a pasar de la experiencia de la desaparición... momentánea, a la de la inexistencia... permanente ( $c f$. Batista, 2011, p. 28). Si Freud reconoce que la realidad tiene un lugar fundamental en el duelo, es justamente porque en el cumplimiento de esa confrontación se juegan el retiro de la libido y la resignación del objeto. Pero, así como no hay sustitución sin resto del objeto perdido, ¿qué asegura que la realidad atestigüe su pérdida? Aún si no podemos descuidar el tardío hallazgo freudiano según el cual, con todo y la diferencia estructural entre neurosis y psicosis, la reconstrucción de la realidad perdida fracasa en ambos casos puesto que no hay sustituto cabal de lo perdido (Freud, 1924/1992, p. 196), la presencia del cadáver es aquí determinante.

Ahora bien, cuando la experiencia de la desaparición no es solo una manera de hablar de la muerte sino la expectativa ante un crimen 
del que no hay otra prueba que la ausencia prolongada del ser en cuestión, y luego, la ausencia del cadáver, ¿qué podemos esperar? ¡Qué duelo es posible en estas condiciones! A falta de duelo hay, por el contrario, eternización del dolor ( $c f$. Pelegrí y Romeu, 2011, p. 141). Pienso que la desaparición -llamada forzada- nos da la medida del horror de la guerra en Colombia cuando del duelo se trata... La desaparición es un traumatismo como ningún otro, que no encuentra las vías de tramitación que serían justamente las del duelo, es una confrontación con lo real de la falta que no termina de ganar la dimensión de la pérdida porque no concluye en la confirmación de la muerte y, tampoco en el reconocimiento del cadáver y el acto del funeral ( $c f$. Zorio, 2011, pp. 251-266).

Si a esto se agrega la indolencia tantas veces denunciada del Estado cómplice cuando no culpable, si, como ha sido la constante en años, la ocurrencia de la desaparición se ha puesto en duda y su valor de crimen ha sido impugnado por las esferas del poder, de nuevo, ¿qué podemos esperar? A falta de reconocimiento, a falta de justicia, en fin, a falta de prueba de realidad que conduciría a declarar muerto al objeto perdido, los deudos han quedado confinados al campo de la pesadilla (cf. Pommier, 1989, p. 133).

No alcanzamos a sopesar el valor y la función de los ritos funerarios, cuyo menosprecio se ha instalado en las sociedades occidentales en paralelo con la devaluación de lo público. De hecho, se ha planteado la pregunta acerca de qué le debe a esta devaluación la epidemia de depresión en el mundo contemporáneo... Pero ese es otro asunto.

II.

Como a mis hermanos los han desaparecido, esta noche espero a las orillas del rio a que baje un cadáver para hacerlo mi difunto.

Así empieza Jorge Eliécer Pardo, escritor colombiano, su relato titulado Sin nombres, sin rostros ni rastros. El relato nos confronta con una de las tragedias más dolorosas de nuestra historia, la de colombianos 
asesinados en el curso de esta guerra irregular que hemos padecido, cuyos cuerpos, arrastrados por las corrientes de los ríos, son avistados por los pobladores de los puertos, recogidos, y adoptados... para ser enterrados. Cuerpos fragmentados de cuyo sufrimiento en vida los pobladores estiman el alcance, y se duelen. Entonces, los adoptan como suyos $\mathrm{y}$, a falta de alguna de sus partes, los completan, los componen.

Desde la perspectiva oficial son los NN, los no name, los sin nombre. Han perdido no solo la vida, también la filiación, aquello que los sitúa en el linaje humano. De nuestra parte, esta tragedia evoca lo innombrable: aquello para lo cual lo simbólico del lenguaje no alcanza, lo que excede a la comprensión, por tanto, a la expectativa imaginaria de aliviar el impacto de terror que provoca, lo que nos enfrenta en cambio a lo real, precisamente a lo que no tiene nombre ${ }^{4}$.

Todos tenemos a nuestros NN en el cementerio, dice una voz del relato, les ofrecemos oraciones y flores silvestres para que nos ayuden a seguir vivos porque los uniformados llegan a romper puertas, a llevarse nuestros jóvenes y a arrojarlos despedazados más abajo para que los de los otros puertos los tomen como sus difuntos en reemplazo de sus familiares (Pardo, 2011, p. 317-320).

En el relato, los pobladores saben, aún si no pueden reconocerlo, que sus desaparecidos están muertos. Pero falta el cadáver. Así, la tragedia de la desaparición encuentra su máxima expresión en la ausencia de las honras fúnebres y de la sepultura. Un documental realizado por los artistas Juan Manuel Echavarría y Fernando Grizáles, titulado Réquiem NN, recoge a su turno la intimidad del ritual que durante años han realizado los pobladores de Puerto Berrio, sobre el Magdalena Medio, escenario privilegiado del accionar paramilitar desde el decenio de 1980. La coincidencia entre el relato literario al que he hecho referencia y el documental mencionado nos permite aproxi-

4 Va aquí mi homenaje a la escritora colombiana Piedad Bonnett.

5 Este relato ocupó el primer puesto en el concurso de cuento sobre desaparición forzada, Sin rastro, convocado por la Fundación Dos Mundos, Instituto Pensar, Pontificia Universidad Javeriana, Comisión Nacional de Búsqueda de Personas Desaparecidas y Defensoría del Pueblo, Colombia, 2008. 
marnos a las razones íntimas de ese sobrecogedor ritual. En efecto, la última escena del filme muestra a una madre, en duelo sin fin, que se acerca a una tumba anónima para cumplirle al difunto allí enterrado la promesa que le hizo de adoptarlo, quiere decir, de nombrarlo: ella le da un nombre, el nombre de su hijo desaparecido...

Entonces, el asunto central en juego en la desaparición es un asunto humano por excelencia: el de dar sepultura a los muertos. No es de extrañar pues, que en este punto evoque yo a Antígona, la heroína que desafía al amo, a Creonte, al contravenir su orden y decidirse a enterrar a su hermano, no porque ella se oponga a la ley, sino porque defiende una ley en acuerdo con la justicia humana (Bruno, 2004, pp. 170-172).

No existe civilización alguna que no haya hecho del cuidado de sus muertos un eje de su cosmovisión y un motivo moral, incluso, aún, la nuestra, la civilización tecno-científica, no obstante sus sueños narcisistas de vencer la muerte, no obstante el hecho de que también la muerte ha ingresado en los cálculos del biopoder y de los más vulgares de la ganancia.

Ahora bien, el ritual del que he presentado aquí a grandes rasgos sus versiones literaria y fílmica, aún si incluye las visitas al cementerio, los rezos, el cuidado de la tumba y la celebración el día de los difuntos, todo eso que podemos recoger como elementos constitutivos de los ritos, empieza por la donación del nombre, no por nada. Del muerto, es el nombre lo que persiste en la memoria de los vivos, aun para dos generaciones sucesivas. Y en el caso anómalo, el de un muerto anónimo, un muerto vivo, un desaparecido, el ritual empieza por ahí. Solo así, una vez nombrado, puede recibir sepultura.

Si el nombre es una marca significante de quienes nos traen a la existencia, que participa de ese movimiento esencial, asegurado por lo simbólico, en virtud del cual una pérdida de lo viviente puro, una pérdida de la condición animal, garantiza nuestro nacimiento como humanos, podemos concluir que ese ritual está a la altura de una redención... Hago aquí mía la reflexión de la psicoanalista M. Menès (2003) para preguntar si acaso la barbarie paramilitar no nos plan- 
teado de la forma más cruda en nuestro medio la pregunta de lo que puede advenir en una cultura en la cual la lógica mortífera llegue a dominar al punto de reducir los cuerpos humanos a lo viviente puro, exterminable como, en efecto, lo inauguró el nazismo ${ }^{6} \ldots$

Así las cosas, mediante su ritual, inscrito en un mundo de creencias que resultan tanto mágicas como religiosas, los habitantes del puerto son aquí los representantes de una humanidad que se niega a entregarle a la barbarie el último baluarte de una costumbre, en sentido ético del término, de una costumbre que nos ha permitido mantenernos aún a salvaguarda de esa lógica: la costumbre de la sepultura. La comunidad expresa una suerte de voluntad colectiva por preservar el principio humano de la sepultura como un legado insustituible, con respecto al cual cada generación tiene que velar por su vigencia para asegurar su transmisión a la siguiente. Los habitantes del puerto saben, sin saberlo, que en ausencia de duelo son las bases mismas de lo humano lo que está en juego. Por lo demás, no esperaron, ni tampoco necesitaron, que organismo alguno, gubernamental o no gubernamental, les dictara el libreto, lo que bien valdría la pena tomar en cuenta.

Dicho de otro modo, el ritual es una tentativa de inscribir lo innombrable, a falta de lo cual no habría memoria posible. Sabemos por Freud que solo la memoria, como inscripción, promete un cambio de registro en la experiencia subjetiva del horror. Lo contrario es el retorno a las imágenes terroríficas, justamente el imperio de la pesadilla. Sabemos, igualmente, que la falta de memoria condiciona la imposibilidad del olvido..., condiciona entonces, para los sufrientes, la imposibilidad de dar vuelta la página.

\section{Referencias bibliográficas}

Agamben, G. (2000). Lo que queda de Auschwitz. El archivo y el testigo. Homo Sacer II. Valencia, España: Pretextos.

6 El original está en francés. La traducción es mía. 
Batista, A. L. (2011). El problema del duelo. Desde el Jardín de Freud: Revista de Psicoanálisis, (11), 17-30. Recuperado de: https://revistas.unal.edu.co/ index.php/jardin/article/view/27214/27483.

Bruno, P. (2004). Ley y arrepentimiento. Desde el Jardín de Freud: Revista de Psicoanálisis, (4), 170-172. Recuperado de: https:/ / revistas.unal.edu.co/ index.php/jardin/article/view/8307/8951.

Elmiger, M. E. (2011). Variaciones actuales de los duelos en Freud. Desde el Jardin de Freud: Revista de Psicoanálisis, (11), 31-50. Recuperado de: https:/ / revistas.unal.edu.co/index.php/jardin/article/view/27215/39629.

Freud, S. (1893-1895/1992). Estudios sobre la histeria (Breuer y Freud). En J. Strachey (Ed.), Obras completas (J. L. Etcheverry, Trad., Vol. II). Buenos Aires, Argentina: Amorrortu.

Freud, S. (1893-1939/1963). Epistolario 1893-1939. Barcelona, España: Biblioteca Nueva.

Freud, S. (1913/1991). Tótem y tabú. En J. Strachey (Ed.), Obras completas (J. L. Etcheverry, Trad., Vol. XIII). Buenos Aires, Argentina: Amorrortu.

Freud, S. (1915/1992). De guerra y muerte. Temas de actualidad. En J. Strachey (Ed.), Obras completas (J. L. Etcheverry, Trad., Vol. XIV). Buenos Aires, Argentina: Amorrortu.

Freud, S. (1917/1992). Duelo y melancolía. En J. Strachey (Ed.), Obras completas (J. L. Etcheverry, Trad., Vol. XIV). Buenos Aires, Argentina: Amorrortu.

Freud, S. (1924/1992). La pérdida de la realidad en la neurosis y la psicosis. En J. Strachey (Ed.), Obras completas (J. L. Etcheverry, Trad., Vol. XIX). Buenos Aires, Argentina: Amorrortu.

Gaitán, G. (2017). El intento de memoricidio de Gaitán. Las dos orillas, abril 10. Recuperado de: https://www.las2orillas.co/delito-mas-alvaro-uribeintento-memoricidio-gaitan-gloria-gaitan/.

León-López, P. (2011). El duelo, entre la falta y la pérdida. Desde el Jardín de Freud: Revista de Psicoanálisis, (11), 67-76.

Menès, M. (2003). Et la chair s'est faite verbe... La lettre de l'enfance et de l'adolescence, 52(2), 9-12.

Pardo, J. E. (2011). Sin nombres, sin rostros ni rastros. Desde el Jardín de Freud: Revista de Psicoanálisis, (11), 317-320. Recuperado de: http://bdigital. unal.edu.co/29263/1/27276-95749-1-PB.pdf.

Pelegrí, M. y Romeu, M. (2011). El duelo, más allá del dolor. Desde el Jardín de Freud: Revista de Psicoanálisis, (11), 133-148. Recuperado de: https:/ / revistas.unal.edu.co/index.php/jardin/article/view/27228/27505.

Pommier, G. (1989). El desenlace de un análisis. Buenos Aires, Argentina: Nueva Visión.

Rabinovich, D. (2003). El concepto de objeto en la teoría psicoanalitica. Buenos Aires, Argentina: Manantial. 
Turnheim, M. (2002). L'autre dans le même. París, Francia: Editions du Champ Lacanien.

Zorio, S. (2011). El dolor por un muerto vivo. Una lectura freudiana del duelo en los casos de desaparición forzada. Desde el Jardín de Freud: Revista de Psicoanálisis, (11), 251-266. Recuperado de: https://revistas.unal.edu. co/index.php/jardin/article/view/27261/27536. 